\title{
PENGARUH PEMBERIAN TEH DAUN TIN (Ficus Carica) DOSIS DUA KALI SEHARI TERHADAP KADAR TOTAL KOLESTEROL PADA MAHASISWA OBESITAS DI POLTEKKES RS dr. SOEPRAOEN MALANG
}

\author{
Bayu Budi Laksono', Mokhtar Jamil ${ }^{2}$ \\ Politeknik Kesehatan RS dr. Soepraoen Kesdam V Brawijaya Malang \\ E-mail : bayubudi87@gmail.com
}

\begin{abstract}
Hypercholesterolemia is a condition when cholesterol levels exceed normal range. Hypercolesterolemia associated with an increased risk of cardio vascular diseases such as Acute Coronary Syndromes (ACS) and Cerebro Vascullar Accident. It is estimated that more than 6 million people suffer from hypercholesterolemia worldwide. College students are a population at risk of suffering from hypercholesterolemia due to an irregular lifestyle accompanied by a lack of physical activity. Tin leaf (Ficus Carica) tea can be used to control cholesterol levels. This research used Quasi experiment design with Repeated measurement (pretest and posttest) design approach. Research Sample were 23 students with obesity who were divided into 2 groups Repeated ANOVA analysis show there are significant differences between groups $(p=0.017)$. Bonferoni Post Hoc analysis shows that there are significant differences between Pretest and post test data in the first week $(p=0.011)$. Flavonoids and pectin in the tin leaf (Ficus carica) play an important role in cholesterol regulation. Flavonoids can increase the expression of HDL-C (good cholesterol), whereas pectin increases the secretion of sterols in Cecal metabolism. Consumption of twice daily tin leave tea was proven in reduce blood cholesterol levels in respondents. It can be conclude there were significant differences of total cholesterol levels before treatment, 1 week after and 2 weeks after administration of Tin (ficus carica) tea leaf with a dose twice a day in Obese College students at the Poltekkes Rumah sakit dr. Soepraoen Malang.
\end{abstract}

Key Words : Cholesterol,College Student, Obesity, Tin (ficus carica)

\begin{abstract}
Abstrak : Hiperkolesterolemia merupakan suatu keadaan ketika kadar kolesterol dalam tubuh melebihi normal. Kelebihan kadar kolesterol dikaitkan dengan meningkatnya resiko penyakit kardio vaskuler seperti Acute Coronary Syndrom (ACS) dan Cerebro Vascullar Accident. Diperkirakan lebih dari 6 juta orang menderita hiperkolesterolemia di seluruh dunia. Mahasiswa merupakan populasi beresiko menderita hiperkolesyterolemia akibat pola hidup yang tidak teratur disertai dengan kurangnya aktifitas fisik. Salah satu terapi yang dapat digunakan untuk mengendalikan kadar kolesterol dalam darah adalah konsumsi teh daun tin (Ficus Carica). Penelitiian ini menggunakan desai Quasi experimental dengan pendekatan Repeated measurement (pre test and post test ) design. Responden penelitian adalah mahasiswa dengan obesitas sejumlah 23 orang tang terbagi dalam 2 kelompok. Hasil analisa Repeated ANOVA menunjukkan terdapat perbedaaan signifikan antar kelompok $(p=0.017)$. Analsi Post Hoc Bonferoni menunjukkan terdapat perbedaan signifikan antara data Pre test dan post test pada minggu pertama $(p=0.011)$. Flavonoid dan pectin dalam the daun tin (Ficus carica) memerankan fungsi penting dalam regulasi kolesterol. Flavonoid mampu meningkatkan ekspresi HDL-C (kolesterol baik), sedangkan pectin meningkatkan sekresi sterol dalam metabolisme Cecal. Konsumsi teh daun tin $2 x$ sehari terbukti mampu menurunkan kadar kolestero darah pada responden. Dari hasil penelitian terbukti terdapat perbedaan signifikan kadar total kolesterol sebelum perlakuan, 1 minggu sesudah dan 2 minggu sesudah pemberian teh daun tin (ficus carica) dengan dosis 2 kali sehari pada Mahasiswa Obesitas di Poltekkes RS dr. Soepraoen Malang.
\end{abstract}

Kata Kunci : Kolesterol, Mahasiswa, Obesitas, Tin (ficus carica)

\section{PENDAHULUAN}

Hiperkolesterolemia merupakan suatu kondisi pada tubuh manusia ketika kadar kolesterol dalam darah melebihi ambang normal. Tingginya kadar kolesterol erat dikaitkan dengan factor resiko kejadian penyakit kardio vaskuler seperti penyakit Acute Coronary Syndrom (ACS) dan Cerebro Vascullar Accident (CVA (Mumpuni \&
Wulandari, 2011). Pemeriksaan kadar kolesterol meliputi pemeriksaan kadar kolesterol secara total serat fraksi nya yang meliputi HDL, LDL dan trigiserida. Angka kolesterol total yag melebihi normal (> $200 \mathrm{mg} / \mathrm{dl}$ ) meningkatkan resiko terjadinya penyakit kardio vaskuler. Tingginya kadar kolesterol darah akan meningkatkan 
kesempatan terbentuknya aterosklerosis yang secara langsung menyebabkan kerusakan lebih lanjut dalam bentuk tekanan darh tinggi, penyakit jantung koroner dan serangan pada pembuluh darah otak (CVA) (Agung, 2014).

Kecadian hiperkolestrol tercatat sangat beragam dalam berbagai sumber. World Heath Organization (WHO) pada tahun 2011 memperkirakan ada lebih dari 200 juta penderita hiper kolesterol di seluruh dunia. American Heart Association (AHA) (2011) menyebutkan bahwa ada lebih dari 6 juta anak dan 36 juta orang dewasa menderita hiperkolesterol di seluruh amerika serikat. Dalam literatut data nasional, diperkirakan $10.1 \%$ dari total penduduk Indonesia mengalami hiperkolesterolemia (Riskesdas, 2013). Lebih jauh lagi, data dinas kesehatan jawatimur mencatat di kota malang $26,1 \%$ laki laki dan $25,9 \%$ perempuan mengalami hiperkolestrolemia (Dinkes, 2014).

Salah satu populasi beresiko menderita hiperkolesterol adalah mahasiswa. Pola aktifitas dan diet yang tidak tertata meningkatkan resiko mahasiswa menderita hiper kolesterol dan obesitas. Faktor genetik dan perubahan gaya hidup dari tradisional ke arah moderenisasi di sebagian kota besar di Indonesia menyebabkan perubahan model konsumsi masyarakat. Diet tinggi kolesterol, lemak dan tinggi kalori menjadi umum dalam pola hidup masyarakat kini. tingginya asupan tinggi kolesterol melalui junkfood dan lemak hewani menyebabkan meningkatnya kadar kolesterol secara pesat (Setiati, 2009).

Kadar kolesterol yang tinggi dalam darah memerlukan penenganan segera. Salah satu pendekatan yang dapat digunakan untuk mengontrol kadar kolesterol dalam darah adalah dengan menggunakan konsumsi bahan herbal. Salah satu tanaman yang telah dikenal mampu mengontrol kadar kolesterol adalah daun tin (ficus carica) (Agung, 2014). Daun tin telah diketahui kaya akan kandungan Flavonoid dan Pecktin yang dipercaya mampu mengendalikan metabolisme kolesterol dalam tubuh. Flavonoid memiliki potensi efektif merilekskan pembuluh darah dan mencegah pembentukan aterosklerosis. $\mathrm{Di}$ sisi lain, Pecktin memiliki mekanisme memicu sekresi cairan empedu pada saluran pencernaan yang akan mengikat kolesterol dan membuangnya keluar tubuh bersama feces. Mekanisme kerja Flavonoid dan Pecktin di atas diperkirakan mampu menurunkan kadar kolesterol dalam darah (Dayanand, 2014). Dari fenomena tersebut, peneliti tertarik untuk melakukan penelitian mengenai pengaruh pemberian teh daun tin (ficus carica) terhadap kadar total kolesterol pada mahasiswa obesitas di Poltekkes RS dr. Soepraoen Malang.

\section{METODE PENELITIAN}

Penelitian ini menggunakan desain penelitian Quasi Experiment dengan metode time series (Rancangan dengan beberapa kali pengukuran berkala). Peneliti melakukan pretest dan dua kali post test pada kelompok control dan perlakuan Bentuk rancangan prepost test with Control Group sebagai berikut :

\section{Tabel 1. Kerangka Kerja Penelitian}

\begin{tabular}{|c|c|c|c|c|}
\hline Kelompok & Pre test & $\begin{array}{c}\text { Mulainya } \\
\text { Perlakuan }\end{array}$ & $\begin{array}{c}\text { Post tes 1 } \\
\text { Minggu 1 }\end{array}$ & $\begin{array}{c}\text { Post tes 2 } \\
\text { Minggh 2 }\end{array}$ \\
\hline Control & $\mathrm{D}_{1}$ & $\mathrm{X}$ & $\mathrm{D}_{2}$ & $\mathrm{D} 1_{3}$ \\
\hline $\begin{array}{c}\text { Dosis 1x } \\
\text { sehar }\end{array}$ & $\mathrm{D} 1_{1}$ & $\mathrm{X}$ & $\mathrm{D}_{2}$ & $\mathrm{D}_{3}$ \\
\hline
\end{tabular}

Sampel yang digunakan dalam penelitian ini adalah sebagian mahasiswa obesitas yang mengalami tinggi kolesterol yang ada di Poltekkes RS dr. Soepraoen Malang sejumlah 26 responden. Sample pada kelompok perlakuan akan mengkonsumsi teh daun tin (1 $\mathrm{gr}$ ) dengan intesitas $2 x$ sehari selama 2 minggu. Pengukuran kadar kolesterol dilakukan sebelum perlakukan, minggu pertama setelah perlakuan dan minggu kedua setelah perlakukan. Setelah data didapatkan, peneliti membandingkan kadar kolesterol. Analisis dilakukan dengan membandingak rerata sebelum pegukuran, satu minggu setelah dan dua minggu setelah dengan pendekatan Repeated ANOVA.

\section{HASIL PENELITIAN}

\section{Gambaran Lokasi Penelitian}

Penelitian dilakukan di Poltekkes RS dr. Soepraoen JI. S. Supriadi no.22 Malang. Poltekkes RS dr. Soepraoen dipilih sebagai tempat penelitian karena angka kejadian obesitas pada responden cukup tinggi yaitu sebesar $13 \%$, usia responden hampir seragam dan aksesibilitas peneliti terhadap responden. Adanya masalah obesitas yang cukup tinggi, jarak yang dekat, kemudahan komunikasi dan koordinasi menjadi alasan utama dilakukannya penelitian. 
Tabel 2. Karakteristik Sampel

\begin{tabular}{|c|c|c|c|}
\hline & \multicolumn{2}{|c|}{ Kelompok } & \multirow{2}{*}{ Total } \\
\hline & Kontrol & $\times 2(2 \times / h r)$ & \\
\hline \multicolumn{4}{|l|}{ Jumblah } \\
\hline & 13 & 13 & $26(100 \%)$ \\
\hline \multicolumn{4}{|l|}{ Jenis Kelamin } \\
\hline Laki-laki & 5 & 3 & $8(30.7 \%)$ \\
\hline Perempuan & 8 & 10 & $18(69.3 \%)$ \\
\hline \multicolumn{4}{|l|}{ IMT } \\
\hline Overweight & 5 & 4 & $9(34.6 \%)$ \\
\hline Obesitas & 8 & 9 & $17(64.4 \%)$ \\
\hline
\end{tabular}

Dalam table 2 disajikan bahwa dari 26 responden lebih dari separuhnya berjenis kelamin perempuan $(69,3 \%)$ dengan IMT (indeks masa tubuh) mayoritas mengalami obesitas dan sisanya dengan overweight (kelebihan berat tubuh).

Tabel 3. Data kadar kolesterol sebelum perlakuan

\begin{tabular}{llllll}
\hline & N & Rata rata & Min & Max & Std dev \\
Kontrol & 13 & 206.54 & 145 & 243 & 30.10 \\
Perlakuan 2x & 13 & 232.46 & 166 & 310 & 36.59 \\
\hline \hline
\end{tabular}

Sebelum dilakukan perlakuan baik kelompok kontrol dan kelompok perlakukan menunjukkan rerata kadar kolesterol berada diatas batas normal. Nilai maksimal kelompok kontrol tercatat 243 $\mathrm{mg} / \mathrm{dl}$ dan nilai minimal $145 \mathrm{mg} / \mathrm{dl}$. Pada kelompok perlakuan menunjukkan nilai tertinggi $310 \mathrm{mg} / \mathrm{dl}$ dan nilai terendah $166 \mathrm{mg} / \mathrm{dl}$.

Table 4. Data kadar kolesterol setelah 1 minggu perlakuan

\begin{tabular}{llllll}
\hline & N & Rata rata & Min & Max & Std dev \\
Kontrol & 13 & 210.23 & 140 & 272 & 37.02 \\
Perlakuan 2x & 13 & 188.07 & 135 & 294 & 46.11 \\
\hline \hline
\end{tabular}

Pada pengukuran kedua tampak bahwa rerata kadar kolesterol pada kelompok kontrol dan perlakuan mengalami perubahan. Rerata kelompok kontrol berada diatas kadar normal $(210.23 \mathrm{mg} / \mathrm{dl})$ sedangkan kelompok perlakuan berada dalam rentang normal $(188.07 \mathrm{mg} / \mathrm{dl})$. Nilai minimal kelompok kontrol tercatat sebesar $272 \mathrm{mg} / \mathrm{dl}$ dan minimal $140 \mathrm{mg} / \mathrm{dl}$. Pada kelompok perlakuan tercatat nilai maksimal $294 \mathrm{mg} / \mathrm{dl}$ dan nilai minimal $135 \mathrm{mg} / \mathrm{dl}$.

Table 5. Data Kadar Kolesterol Setelah 2 Minggu Perlakuan

\begin{tabular}{llllll}
\hline & N & Rata rata & Min & Max & Std dev \\
Kontrol & 13 & 193.00 & 143 & 222 & 24.79 \\
Perlakuan 2x & 13 & 182.92 & 128 & 290 & 47.40 \\
\hline \hline
\end{tabular}

Pada pengukuran yang dilakukan di minggu kedua setelah perlakukan tampak bahwa rerata kadar kolesterol responden terus mengalami penurunan pada kelompok perlakuan $(182,92 \mathrm{mg} / \mathrm{dl})$ meskipun kelompok kontrol juga menunjukkan penurunan rerata $(193 \mathrm{mg} / \mathrm{dl})$. Nilai maksimal kelompok kontrol tercatat $222 \mathrm{mg} / \mathrm{dl}$ dengan nilai minimal $142 \mathrm{mg} / \mathrm{dl}$, sedangkan pada kelompok perlakukan tercatat kadar maksimal $290 \mathrm{mg} / \mathrm{dl}$ dan kadar terendah $126 \mathrm{mg} / \mathrm{dl}$. Analisa lebih lanjut terhadap penurunan kadar kolesterol dapat diamati pada diagram berikut : 


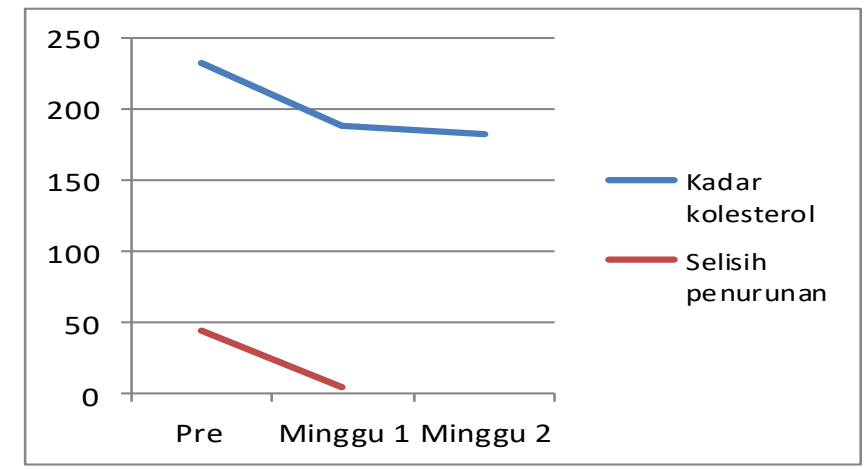

Gambar 1. Penurunan kadar kolesterol

Table 6. Analisa Pengaruh Teh Daun Tin Terhadap Kadar Kolesterol Setelah 2 Minggu Perlakuan

\begin{tabular}{|c|c|c|c|}
\hline & Is & \multicolumn{2}{|c|}{ p Vakue } \\
\hline Pre & 13 & \multicolumn{2}{|c|}{$0.972 *$} \\
\hline Minggu 1 & 13 & \multicolumn{2}{|c|}{$0.119 *$} \\
\hline \multirow[t]{3}{*}{ Minggu 2} & 13 & \multicolumn{2}{|c|}{$0.052 *$} \\
\hline & \multicolumn{3}{|l|}{ Saphino Wille } \\
\hline & Rata rata (Std Dev) & \multicolumn{2}{|c|}{ p Malue } \\
\hline Pre & $232.46(36.60)$ & \multicolumn{2}{|c|}{$0.017 *$} \\
\hline Minggu 1 & $18 s .0 \sin (411)$ & & \\
\hline \multirow[t]{3}{*}{ Minggu 2} & $182.92(47.40)$ & & \\
\hline & Repected ANOVA & & \\
\hline & Selisish rata rata & $\operatorname{IK} 9596$ & P Malue \\
\hline Pre $>$ Mingen 1 & 44.39 & $9.88-78.88$ & $0.011 \%$ \\
\hline Pre $>$ Minggu 2 & 49.54 & $5.33-93.74$ & $0.027 *$ \\
\hline Minggu $1>$ Minggu 2 & 5.15 & $-22.49-32.80$ & 1.000 \\
\hline & Bonferoni & & \\
\hline
\end{tabular}

Hasil analisa normalitas pada table 6 menunjukkan bahwa data layak diproses dengan menggunakan metode parametric Repeated ANOVA $(p>0,05)$. Hasil analisa Repeated ANOVA menunjukkan $p$ value $=0,017$ yang bermakna ada setidaknya satu perbedaan signifikan diantara kelompok. Untuk mengetahui perbedan lebih lanjut dilakukan uji Post Hoc Benferoni. Hasil uji Post Hoc menunjukkan bahawa terdapat perbedaan yang signifikan antara kadar kolesterol sebelum perlakuan dengan satu minggu setelahnya $(p=0,011)$ dan antara kadar kolesterol sebelum perlakuan dengan dua minggu setelahnya $(p=0.027)$.

\section{PEMBAHASAN}

Kadar Total Kolesterol Sebelum Pemberian Teh Daun Tin (Ficus Carica) Pada Mahasiswa Obesitas Di Poltekkes RS Dr. Soepraoen Malang

Kadar kolesterol pada kedua kelompok berada dalam batas atau di atas batas kolesterol normal. Kadar terendah pada sampel kontrol sebesar $145 \mathrm{mg} / \mathrm{dl}$ dengan kadar maksimal $234 \mathrm{mg} / \mathrm{dl}$. Sedangkan pada kelompok perlakuan $2 x$ sehari menunjukkan kadar terendah $166 \mathrm{mg} / \mathrm{dl}$ dan kadar tertinggi $310 \mathrm{mg} / \mathrm{dl}$.

Kolesterol adalah komponen putih yang secara alami ditemukan di dalam jaringan tubuh. Kolesterol dibagi menjadi beberapa bagian, umumnya yang diketahui yaitu LDL (Low Density Lipoprotein) dan HDL (Hight Density Lipoprotein) (Fifinella, 2008). Kadar kolestrol dipengaruhi olah beberapa hal, salah satunya adalah pola hidup. Pola hidup masyarakat yang banyak mengkonsumsi makanan junkfood dan makanan berlemak meningkatkan asupan kolesterol mengakibatkan kadar kolesterol meningkat (Setiati, 2009). Dalam literature lain disebutkan, pola hidup yang tidak teratur seperi diet tinggi lemak dan kurangnya aktifitas fisik dapat menyebabkan terjadinya hiperkolesterol dan obesitas (Anggraini, 2008).

Berdasarkan fakta dan teori di atas menunjukkan tingginya kadar kolesterol pada responden diduga berkaitan erat dengan pola hidup. Asupan tinggi kolesterol berupa lemak hewani dan junkfood serta pola aktifitas kemungkinan besar memberikan pengaruh terhadap tingginya kadar kolesterol pada responden. 
Kadar Total Kolesterol 2 Minggu Sesudah Pemberian Teh Daun Tin (Ficus Carica) Dengan Dosis 2 Kali Sehari Pada Mahasiswa Obesitas Di Poltekkes RS Dr. Soepraoen Malang

Hasil pada minggu ke dua tampak bahwa rata rata kadar kolesterol menunujukkan angka dalam batas kadar kolesterol normal baik pada akelompok control maupun kelompok perlakuan dengan dosis $2 x$ sehari.

Louwajri dan Tchombe (2015) menyampaikan bahwa batang daun dan buah dari fikuscarica telah lama digunakan sebagai obat tradisional pada gangguan gastrointestinal, respirasi, diabetes, penyakit kulit, luka disentri dan hemoroid serta banyak penyakit lain. Daun Ficus Carica (tin), memiliki zat aktif alkali, asam lemak, alkohol, Phytosterol dan triterpenoid yang bermanfaat bagi tubuh manusia. Substasi asam lemak berfungsi sebagai anti oksidan. Phytosterol mampu menghambat secara aktif penyerapan kolesterol dalam saluran pencernaan (Ivanov et al, 2018).

Kandungan zat aktif dalam daun tin diduga mampu memberikan pengaruh terhadap kadar kolesterol. Sejalan dengan teori, rerata kadar kolesterol pada responden menunjukkan hasil yang normal setelah mengkonsumsi teh daun tin selama 2 minggu. Kandungan asam lemak dan Phytosterol diduga sebagai agen aktif yang mempengaruhi mekanisme penurunan kadar kolesterol pada tubuh manusia.

Pengaruh Pemberian Teh Daun Tin (Ficus Carica) Dengan Dosis 2 Kali Sehari Pada Mahasiswa Obesitas Di Poltekkes RS Dr. Soepraoen Malang

Pengujian rerata kadar kolesterol pada dosis $2 \mathrm{x}$ sehari dengan menggunakan pendekatan uji Repeated ANOVA menunjukkan adanya paling tidak 1 perbedaan yang signifikan antar kelompok. Uji post hoc metode bonferoni menunjukkan terjadi penurunan kadar kolesterol yang signifikan pada minggu pertema setelah pemberian teh daun tin dengan dosis 2 kali sehari.

Efek flavonoid dalam menurunkan kadar kolesterol telah banyak diteliti. Pemberian qwercetin glicosida (sejenis flavonoid) oral pada tikus menunjukkan mengakibatkan penurunan kadar lemak pada plasma dan jaringan. HDL-C meningkat disertai dengan menurunnya LDL-C dan VLDL-C. Flavonoid dapat menurunkan kadar kolestrol darah melalui proses inhibisi sintesis kolestrol dan meningkatkan ekspresi reseptor LDL ( Zeka, Rupareliya, Arroo, Budriesih dan Micucci, 2017). Flavonoid mampu meningkatkan fungsi HDL melalui mekanisme anti inflamasi dan antioksidan pada sel. Dalam penelitian lain juga dilaporkan bahwa flavonoid mampu menurunkan kadar metabolisme lipid dan arterokleosis pada hewan serta meningkatkan kadar HDL pada beberapa kasus (Millar, Duclos dan Blesso, 2017).

Pectin mampu meningkatkan ekskresi sterol yang mengakibatkan efek penurunan kolestrol. Sebuah studi menunjukkan bahwa pectin mampu meningkatkan berat cecum dan mempengaruhi metabolisme cecal namun tidak memiliki efek signifikan pada homeostatis kolestrol dengan mekanisme yang belum diketahui (Marounek, Volek, Synytsya dan Copikova, 2007). EFSA (2010) menyatakan bahwa konsumsi pectin dalam makanan memberikan efek reduksi kadar gula darah dan menjaga kadar kolestrol darah dalam batas normal. Penelitian yang menggunakan ekstrak daun ficus carica pada hewan coba dengan diabetes menunjukkan hasil positif berupa penurunan kadar kolestrol pada sel hati. Meskipun terdapat penurunan, mekanisme dari penurunan kadar kolestrol pada percobaan tersebut masih belum jelas. (Marwat, Han, Han Rehman, Akbari, Akhmad, Zhafar dan Akhmad, 2011).

Peneliti menduga bahwa flavonoid dan pectin memerankan fungsi penting dalam regulasi kolesterol. Flavonoid mampu meningkatkan ekspresi HDL-C (kolesterol baik), sedangkan pectin meningkatkan sekresi sterol dalam metabolisme Cecal. Konsumsi teh daun tin $2 x$ sehari terbukti mampu menurunkan kadar kolesterol darah pada responden.

\section{KESIMPULAN}

1. Kadar total kolesterol sebelum pemberian teh daun tin (ficus carica) pada Mahasiswa Obesitas di Poltekkes RS dr. Soepraoen Malang menunjukkan rerata kadar kolesterol mendekati atau diatas batas kadar kolesterol normal.

2. Kadar total kolesterol 2 minggu sesudah pemberian teh daun tin (ficus carica) dengan dosis 1 kali sehari dan 2 kali sehari terhadap kadar total kolesterol pada Mahasiswa Obesitas di Poltekkes RS dr. Soepraoen Malang menunjukkan rerata kadar kolesterol dalam batas normal.

3. Terdapat perbedaan signifikan kadar total kolesterol sebelum perlakuan, 1 minggu sesudah dan 2 minggu sesudah pemberian teh daun tin (ficus carica) dengan dosis 2 kali sehari pada Mahasiswa Obesitas di Poltekkes RS dr. Soepraoen Malang. 


\section{SARAN}

1. Perlu dilakukan penelitian lebih lanjut untuk mengetahui kandungan rinci pada the daun tin (ficus carica).

\section{DAFTAR PUSTAKA}

Agung, I. 2014. Dahsyatnya Tin \& Zaitun Tumpas Penyakit Kronis \& Berbahaya. Surakarta: Al-Qudwa Publishing.

Alam. Imran., et al.2011. A Review On Traditional, Pharmacological, Pharmacognostic Properties Of Ficus Carica. International Journal Of Pharmacy \& Life Sciences 2 (12), 124127.

Almatsier S. 2009. Prinsip Dasar IImu Gizi. Jakarta: Gramedia Pustaka Utama.

American Heart Association.2011. Metabolic risk for cardiovascular disease edited by Robert H. Eckel. Wiley -Blackwell Publishing.

Badan Penelitian dan Pengembangan Kesehatan. 2007. Riset Kesehatan Dasar (Riskesdas) 2007: Laporan Nasional. Jakarta: Badan Litbangkes Depkes.

Badan Penelitian dan Pengembangan Kesehatan. 2013. Riset Kesehatan Dasar (Riskesdas) 2013: Laporan Nasional. Jakarta: Badan Litbangkes Depkes.

Brouns, Theuwissen1, Adam, Bell, Berger and Mensink. 2012. Cholesterol-lowering properties of different pectin types in mildly hyper-cholesterolemic men and women. European Journal of Clinical Nutrition (2012) 66, 591-599

Cappello, Dolce, lacopetta, Martello, Fiorillo, Curcio, Muto and Dhanyalayam. 2015. Bergamot (Citrus bergamia Risso) Flavonoids and Their Potential Benefits in Human Hyperlipidemia and Atherosclerosis: an Overview. MiniReviews in Medicinal Chemistry, 2015, $15,000-000$

Dayanand, K., et al. 2014.Global Journal For Research Analysis; Phytochemical Investigation and Evaluation of Antihyperlipidemic Activity of Ficus Carica Linn leaf Extracts. Vol. 3, Is. 6: 184-187

Depkes. 2008. Pedoman praktis terapi gizi medis Departemen Kesehatan Republik Indonesia.

EFSA .2010. Scientific Opinion on the substantiation of health claims related to pectin and reduction of post-prandial glycaemic responses (ID 786), maintenance of normal blood cholesterol
2. Perlu dilakukan pengkajian lebih jauh tentang dosis efektif pada penggunaan teh daun tin (ficus carica).

concentrations (ID 818) and increase in satiety leading to a reduction in energy intake (ID 4692) pursuant to Article 13(1) of Regulation (EC) No 1924/20061. EFSA J 8, 174.

Fifinella, V. 2008. Awas, Bahaya Laten Kolesterol. Bantul Yogyakarta: In Azna Books

Gibney. 2009. Gizi Kesehatan Masyarakat. Jakarta: EGC.

Harti, A. S.2014. Biokimia Kesehatan. Yogyakarta: Nuha Medika.

Indiasari, R. 2012. Hubungan Pola Makan Dengan Kejadian Obesitas Pada Remaja di SMA Katolik Cendrawasih.

Ivanov, Dincheva, Badjakov, Petkova, Denev and Pavlov. 2018. GC-MS analysis of unpolar fraction from Ficus carica L. (fig) leaves. International Food Research Journal 25(1): 282-286

Joerin ,Lorenz., Kauschka , Michaela., Bonnländer, Bernd ., Pischel ,Ivo ., Benedek , Birgit and Butterweck ,Veronika. 2013. Ficus carica Leaf Extract Modulates the Lipid Profile of Rats Fed with a High-Fat Diet through an Increase of HDL-C. Phytotherapy Reseach Volume28, Issue2 February 2014 Pages 261-267 https://doi.org/10.1002/ptr.4994

Khasanah, Nur.2011. Kandungan Buah-Buahan Dalam Alqur'an: Buah Tin (Ficus Carica L), Zaitun (Olea Europea L), Delima (Punica Granatum L), Anggur (Vitis Vinivera L), Dan Kurma (Phoenix Dactylifera L) Untuk Kesehatan.

Kim ,Youngyo and Je, Youjin. 2017. Flavonoid intake and mortality from cardiovascular disease and all causes: A meta-analysis of prospective cohort studies. j.clnesp.2017.03.004 DOI: https://doi.org/10.1016/j.clnesp.2017.03. 004

Luo , Yuanyuan., Shang ,Pingping and Li, Dongye . 2017. Luteolin: A Flavonoid that Has Multiple Cardio-Protective Effects and Its Molecular Mechanisms. Frontiers in Pharmacology October 2017 | Volume 8 article 692. doi: 10.3389/fphar.2017.00692

M Assini, Julia \& Mulvihill, Erin \& W Huff, Murray. 2012. Citrus flavonoids and lipid metabolism. Current opinion in 
Bayu Budi Laksono, Pengaruh Pemberian Teh...| 89

lipidology.

10.1097/MOL.0b013e32835c07fd.

24.

MacKay, D. S and Jones, P. J. H. 2011. Phytosterols in human nutrition: Type, formulation, delivery, and physiological function. European Journal of Lipid Science and Technology 113: 14271432.

Marmi. 2013. Gizi dalam Kesehatan Reproduksi. Yogyakarta: Pustaka Belajar.

Marounek, Volek, Synytsya Dan Čopíková. 2007. Effect of Pectin and Amidated Pectin on Cholesterol Homeostasis and Cecal Metabolism in Rats Fed a HighCholesterol Diet. Physiol. Res. 56: 433442, 2007

Marwat, sarfarez., han, Muhammad aslam., han, mir ajab., rehman, fazal., akbari, abdul hakim., ahmad, mushtaq., zafar, Muhammad, dan ahmad, farooq. 2011. Medicinel $n$ parmakologikal potentiality of the plant at-tin-commen fig (ficuscarica L.). Asian Jurnal Of Chemistry; vol. 23, no. 1 (2011), pp 1 10

Millar, Duclos, and Blesso. 2017. Effects of Dietary Flavonoids on Reverse Cholesterol Transport, HDL Metabolism, and HDL Function. American Society for Nutrition. Adv Nutr 2017;8:226-39; doi:10.3945/an.116.014050

Misnadiarly.2007. Obesitas sebagai Faktor Resiko beberapa Penyakit. Jakarta: Pustaka Obor Populer.

Mumpuni, Yekti \& Wulandari, Ari.2011. Cara Jitu Mengatasi Kolesterol. Yogyakarta: Andi Publisher

Nadimin. 2011. Pola Makan, Aktivitas Fisik dan Status Gizi Pegawai Dinas Kesehatan Sulawesi Selatan. Media Gizi Pangan, Vol. 11, Edisi 1.

Notoatmodjo. 2010. Metodologi Penelitian Kesehatan. Jakarta : Rineka Cipta

Nurrahmani. 2012. Stop Hipertensi. Jogjakarta: Familia.

Pang, Yuxin., Zhang ,Yan., Huang, Luqi., Xu , Luofeng ., Wang, Kai ., Wang ,Dan., Guan , Lingliang., Zhang , Yingbo., Yu ,Fulai ., Chen ,Zhenxia dan Xie ,Xiaoli .2017. Effects and Mechanisms of Total Flavonoids from Blumea balsamifera (L.) DC. on Skin Wound in Rats. Int. J. Mol. Sci. 2017, 18, 2766; doi:10.3390/ijms 18122766

Refli, R. 2012. Potensi Ekstrak Daun Tin (Ficus Carica) Sebagai Antioksidan Dan Aktivitas Hambatannya Terhadap Proliferasi Sel Kanker Hela

Rinanto, J. 2015. Keajaiban Resep Obat Nabi S.A.W.: Menurut Sains Klasik \& Modern. Jakarta: Qisthi Press.
Saryono. 2011. Metodologi penelitian keperawatan. Purwokerto: UPT Percetakan dan Penerbitan UNSOED.

Setiadi. 2007. Konsep Dan Penulisan Riset Keperawatan. Yogyakarta: Graha Ilmu.

Setiati, E. 2009. Bahaya Kolesterol, Mengenal, Mencegah dan Menanggulangi Kolesterol. Yogyakarta: Dokter Books, hlm. 31-32, 36.

Takahashi, Toru., Okiura , Aya., Saito, Keita and Kohno ,Masahiro . 2014 Identification of Phenylpropanoids in Fig (Ficus carica L.) Leaves. J. Agric. Food Chem., 2014, 62 (41), pp 10076-10083 DOI: $10.1021 / \mathrm{jf5025938}$

Tchombe and Louaji. 2015. Therapeutic Effects of Ficus Carica Leaves: A Brief Review. ARPN Journal of Science and Technology VOL. 5, NO. 1, January 2015

Terpstra A.H, Lapre JA, de Vries HT, Beynen AC.2002. The hypocholesterolemic effect of lemon peels, lemon pectin, and the waste stream material of lemon peels in hybrid F1B hamsters. Eur J Nutr 41, 19-26.

Tunggul, W. 2013. Hubungan Antara Konsumsi Pangan Dan Aktivitas Fisik Dengan Kadar Kolesterol Darah Pria Dan Wanita Dewasa Di Bogor. JGP, Vol. 8, No. 1.

Umam, Abidul.2014. Ajaibnya Khasiat Daun Dan Buah Tin Penyembuh Segala Penyakit. Semarang: Griya Mulya Indah.

Wadhera, Rishi., Steen, Dylan L., Khan , Irfan., Giugliano ,Robert P dan Foody ,JoAnne M. 2016. A review of low-density lipoprotein cholesterol, treatment strategies, and its impact on cardiovascular disease morbidity and mortality. Journal of Clinical Lipidology (2016) 10, 472-489. http://dx.doi.org/10.1016/.j.jacl.2015.11.0 10

Wang, Shaohua., Cai, Rongrong., Yuan ,Yang., Varghese ,Zac, Moorhead, John dan Ruan, Xiong. 2017. Association between reductions in low-density lipoprotein cholesterol with statin therapy and the risk of new-onset diabetes: a metaanalysis. Scientific Reports 7:39982 | DOI: 10.1038/srep39982

WHO. 2011. World Health Organization (WHO) Technical Report Series: Diet, Nutrition and the Prevention of Chronic Diseases.

Zeka, Ruparelia, Randolph, Arroo, Budriesi and Micucci. 2017. Flavonoids and Their Metabolites: Prevention in Cardiovascular Diseases and Diabetes. Diseases 2017, 5, 19; doi:10.3390/diseases5030019 